\title{
Processos de criação da Companhia de Dança Contemporânea da UFRJ no contexto da ciência \& arte
}

André Meyer. Universidade Federal do Rio de Janeiro, Rio de Janeiro, RJ; Email: <andremeyer@ufrj.br>.

Ana Célia de Sá Earp. Universidade Federal do Rio de Janeiro, Rio de Janeiro, RJ; Email: <anaceliaearp@gmail.com>.

Sara Cohen. Escola de Música, Universidade Federal do Rio de Janeiro, Rio de Janeiro, RJ; Email: <saracohen@uol.com.br>.

\section{Resumo}

Este trabalho visa refletir sobre os processos intermidiáticos de roteirização e montagem coreográfica dos espetáculos "Transições" e "Anatomia dos Contatos" da Companhia de Dança Contemporânea da UFRJ. Inicialmente são explicitadas relações entre ciência e arte tomando como referência a Hiperfenomenologia de François Dagognet, a partir da qual são abordadas questões-chaves da pesquisa, tais como: método morfológico e grafismo figurativo-simbólico, evidenciando o papel primordial que faz da imagem-símbolo o fundamento das ciências contemporâneas. A arte contemporânea é analisada como uma arte de interação multimidiática e plurisensorial, enfaticamente corporal e performática. Dentro deste contexto, vem se intensificando a presença de temas científicos como fonte de inspiração para a criação de espetáculos coreográficos. O trabalho demonstra como os Fundamentos da Dança de Helenita Sá Earp foram aplicados: a) na estetização coreográfica de mudanças estruturais e conformacionais celulares, moleculares e sub-moleculares presentes no modelo de regulação e homeostasia do cobre em leveduras que foi utilizado na roteirização do espetáculo multimídia "Transições" e b) na interação com a música através do uso de ruídos eletroacústicos, sonoridades desconstruídas, guitarra estruturada, sons da respiração, voz e percussão sinfônica juntamente com a pesquisa dos contatos e apoios do espetáculo "Anatomia dos Contatos". Assim como Dagognet ressalta a epistemologia de índole estética na atualidade, este artigo aponta para uma poética intermidiática na dança como forma de arte contemporânea.

Palavras-chave: Ciência e Arte, Processos de Criação, Fundamentos da Dança de Helenita Sá Earp, Intermidialidades.

\section{Ciência, Arte e Intermidialidade}

Ao dirigir sua reflexão para a ciência e para a arte contemporâneas, François Dagognet tem como intenção 
primordial mostrar que existe um entrelaçamento muito íntimo entre epistemologia e estética. A leitura atenta de seus escritos nos coloca frente aos binômios - razão e imaginação, ciência e arte - como temas centrais de seu pensamento. Em sua reflexão sobre as ciências contemporâneas, Dagognet exalta o método morfológico, através do qual se é possível pesquisar as superfícies das formas. Este saber hiperfenomenalista se faz nas superfícies, nas camadas, nos cortes, nas vistas, para assim, penetrar nos dados, no que há para observar com a intenção de interpretá-los (Michaud, 1992: 31).

Todo este arcabouço de saberes gerado pela investigação morfológica e morfogenética em diferentes áreas da pesquisa científica se expressa numa linguagem pictórica apoiada na imagem técnica que registra, descreve, transcreve e trata os dados. "Assim, a expressão como conquista, a importância do desenho e da representação, em suma, uma defesa da escrita, a glória, tanto estética quanto científica, da Figuração" (Dagognet, 1975: 7).

Neste sentido, há uma valorização na epistemologia de Dagognet, da transcrição verbo-gráfica, da caligrafia, do desenho, do croqui, do esquema, do quadro sinótico, da equação, do mapa, que são considerados como uma espécie de "pintura" ou story board racional. Esta abordagem se intensifica no pensamento de Dagognet a medida em que ele reflete que na contemporaneidade há um abandono dos pontos de vista lineares em prol da pesquisa multi-intertransdisciplinar, o que ocasiona descobertas oriundas da interação entre as diferentes áreas de saber. Tudo isso pode ser evidenciado na citação abaixo:

Ao ressaltar o método morfologizante e o simbolismo pictórico da ciência, se fundamenta na ideia de que a representação visual e o símbolo intelectual se unem através da imagem-símbolo como o fundamento primordial da atividade científica da atualidade, mostrando 0 papel primordial que a imagem desempenha nas ciências (Bulcão, 2010: 39). 
Em várias de suas obras, Dagognet faz uma reflexão sobre a arte contemporânea. O artista, tal como o cientista, é aquele que descobre um acesso novo ao real, experimenta um insólito contato, prova um ingrediente desconhecido para libertar e oferecer um substrato ignorado. ${ }^{1}$ Desta forma, Dagognet fundamenta o trabalho do artista a partir dos materiais presentes em suas obras, nas técnicas de fabricação e nos protocolos de criação explorados. Dagognet ressalta que a arte contemporânea é uma arte de interação plurisensorial, enfaticamente corporal e performática; na medida em que tem por finalidade primeira provocar novos acessos à matéria e ampliar suas utilizações e meios de fruição. Enfatiza que não faz sentido elaborar uma epistemologia depurada da imagem assim como ressalta a importância dos protocolos técnicos na arte contemporânea, como montagens experimentais:

Assim, a maioria das obras de arte contemporâneas corresponde a uma espécie de montagem, ou ao menos, às tentativas quase experimentais, destinadas para nos revelar um real desconhecido, cheio de surpresas; enquanto o erudito, no seu laboratório, tenta tirar da materialidade aquilo que ela esconde, da mesma forma que, no seu ateliê, o artista dedica-se às provas, os quais transformam a idéia fundamental e conseguem abri-la (Dagognet, 2002: 13).

A relação entre a ciência e a arte contemporâneas fica bem evidenciada quando ele diz: "Atrevemos-nos, portanto, misturar 'arte e ciência', aproximar todos estes trabalhadores do 'multiaxial' ou do 'projetável', estes escritores da iconografia" (Idem, 1975: 12), cujas interfaces com a dança passaremos a refletir.

Intermidialidades nos Fundamentos da Dança de Helenita Sá Earp

1 Ver Pour l'art d'aujourd'hui, de l'objet de l'art à l'art de l'objet. Paris: Editions Dis voir, 1992: 99. Ver também: Rematérialiser, Paris: Jean Vrin, 1985: 85 e Corps réflechis. Paris: Odile Jacob, 1990. 
Os Fundamentos da Dança de Helenita Sá Earp ${ }^{2}$ possuem um conjunto de princípios filosóficos, pressupostos epistemológicos e metodológicos que são capazes de instaurar agentes diversificadores da linguagem corporal no desenvolvimento integrado de habilidades motoras, interpretativas e criadoras. Os Parâmetros da Dança: Movimento, Espaço, Forma, Dinâmica e Tempo e seus Agentes de Variação possuem uma consistência interna em relações de sistematicidade que propiciam a interação da linguagem da dança com as demais áreas do conhecimento (Earp, A. 2010: 2). Como não se tem nenhum padrão de movimento a seguir e como a pesquisa de movimento é ilimitada, uma pessoa pode dançar a partir de diferentes tipos de sons, palavras, poesias, desenhos, pinturas, croquis, mapas, instalações, equações, teorias científicas, textos filosóficos, luminosidades, fotografias, filmes; portanto de toda e qualquer situação que seja instauradora de uma mobilização poética, seja ela qual for. A metodologia de ensino de dança proposta por Helenita não é fechada porque parte de situações exploratórias originárias presentes nos próprios atributos intrínsecos da corporeidade, em seus aspectos de movimento, espaço, forma, dinâmica e tempo. Estes atributos estão presentes na corporeidade humana como também nos demais fenômenos do universo. Neste sentido, são princípios universais que estão presentes em todas as coisas. Isto nos permite, por exemplo, relacionar a dança com as geometrias topológicas, pois forma, função, estrutura, arranjo e configuração se caracterizam como aspectos comuns das artes e ciências.

Com isto podemos relacionar o movimento corporal e entende-lo como pertencente à corporeidade de todas as coisas, o que facilita o uso de imagens e símbolos, em estreita vinculação com o conhecimento detalhado da

\footnotetext{
2 Professora Emérita de Dança da UFRJ (1919 - 2014). Introdutora da dança no ensino das universidades brasileiras em 1939.
} 
diversificação do movimento. Deste modo, tanto a linguagem anatômica (objetiva e científica) quanto a linguagem metafórica (simbólica e artística) podem interagir mais, sem dicotomias. $\mathrm{O}$ conhecimento anatômico e cinesiológico, fecundado pela criatividade, além de revelar-se e integrar-se em si mesmo, também pode ser relacionado com a corporeidade do universo em diferentes abordagens e temáticas presentes nas ciências, artes e filosofias (Meyer, 2012: 101).

Todos os parâmetros estão intimamente ligados e a delimitação e sua organização em separado é um eficaz recurso didático para o ensino e a criação na dança através de:

1) Redes de conhecimentos na dança gerados por como princípios e agentes diversificadores da linguagem da dança em diferentes relações no desenvolvimento integrado de habilidades motoras, interpretativas e criadoras; 2) Conceitos e imagens do corpo nas suas relações com o Movimento, o Espaço, Forma, Tempo e Dinâmica; que se conformam através de uma interpenetração orgânica com processos de improvisação; 3) Técnica criativa e estudo da composição coreográfica gerando competências múltiplas dentre de um mesmo enfoque temático; 4) Constelações de conhecimentos advindos da interação entre a linguagem da dança com demais manifestações e modalidades artísticas na constituição de múltiplos enfoques de roteirização e encenação coreográfica; 5) Desenvolvimento de conexões da linguagem da dança com o conhecimento da sua fisicalidade advindos de conteúdos das ciências, tais como anatomia, cinesiologia, bioquímica, matemática, geometria, história, física, biologia, entre outras e 6) Enfoque numa pedagogia de inovação que promova a instauração de diversas estruturas e tipos de aulas capazes de fornecer subsídios para a criação de diferentes práxis de ensino de dança mais coadunada com os desafios da dança no contexto da arte contemporânea (Earp, A. , 2010: 7 e 8).

Neste sentido, os processos experimentais de pesquisa coreográfica desenvolvidos na montagem de "Transições" e "Anatomia dos Contatos" ${ }^{3}$ partem da visão presente nos Fundamentos da Dança de Helenita Sá Earp onde a dança é intrínseca a todas as manifestações sonoras, plásticas e cromáticas (Earp, R. 1992).

${ }^{3}$ Espetáculos que contaram com o apoio financeiro da FAPERJ através dos Editais de Difusão e Popularização da Ciência - 2008 / 2012. 


\title{
Dança e Ciência
}

Na segunda metade do século $X X$, as ciências da informação atravessam uma fase de intensa mudança que serão açambarcados pelo universo da arte. $\mathrm{Na}$ efervescência dos anos 60 , novos paradigmas plasmaram-se em manifestações como a body art, instaurando uma re-corporificação do corpo no espaço cibernético, como detalhado abaixo:

\begin{abstract}
A história da arte exemplifica uma série de complexas relações entre o corpo e o espaço. Negociação entre a visão do corpo no espaço real e a sua representação no domínio virtual. O espaço contemporâneo do corpo não está mais vinculado à noção moderna que fundamenta o modelo de corpo no balé clássico. Nosso espaço tem uma localização em vertigem, literalmente de cabeça para baixo, está lançado no espaço, é declarado obsoleto e agora super-humano ou além do homem na re-corporificação do corpo no espaço cibernético (Shaw, 1999: 6).
\end{abstract}

A evolução da multimídia nas décadas de 60 e 70 permitiu o surgimento de poéticas coreográficas onde o espectador participava junto à cena na construção do tecido cênico. Hoje, o corpo virtualmente representado também assume o papel de protagonista da construção coreográfica, ampliado pela conjunção ativa entre espectador e obra. O corpo e o espaço são as sementes dessas conjunções e extensões.

A representação do corpo na contemporaneidade promove um crescente questionamento sobre a relação com a técnica. Novas configurações corporais se impõem por meio das tecnologias médicas e cibernéticas. Com o desenvolvimento tecnológico atual, tais intervenções foram se intensificando em níveis de sofisticação que possibilitam a emergência de exibições que adentram internamente o corpo, seus músculos, órgãos e fluidos.

Teoria do Caos, sistemas complexos, auto-poiéses, algoritmos genéticos, memes, são expressões do novo paradigma em campos técnicos e científicos que atingem por completo a dança contemporânea. 
A valorização do uso da imagem nas ciências biológicas contemporâneas tem suscitado a criação de propostas estéticas na encenação coreográfica na atualidade. Muitas descobertas científicas em química, biologia celular, terapia com células tronco e engenharia genética, se tornaram objeto de temas da pauta artística na dança, estabelecendo uma multiplicidade de diálogos que interligam as dimensões artísticas com as científicas, envolvendo para tanto equipes acadêmicas de pesquisadores de universidades.

Para que isto possa ocorrer de modo fecundo, é necessário que a dança seja entendida como uma linguagem artística aberta e, portanto, capaz de traduzir questões da filosofia da natureza e das ciências, como podemos ver a seguir em alguns dos processos de criação desenvolvidos pela Companhia de Dança Contemporânea da UFRJ.

\section{Processos de criação intermidiáticos em "Transições"}

"Transições" é um espetáculo multimídia de dança que faz uma descida vertiginosa do mundo do macro ao mundo do micro, apresentando de forma poética e filosófica o percurso de um cientista que sai do cosmos até chegar ao interior de uma célula. Esta obra se caracteriza pela interação de movimento, poesia e projeção mapeada. "Transições" teve como leitmotiv 4 norteador o esquema sobre regulação e homeostasia de cobre em leveduras. ${ }^{5}$

4 Renato Cohen em seu livro Work in Progress na Cena Contemporânea cita que "O termo leitmotiv é originário da música e literatura: uma tradução possível seria vetor, dando conta dos diversos impulsos que compõem a narrativa" (1999, p. 25).

${ }^{5}$ Modificado de http://www.bioinformatics.med.uu.nl/courses/blast/. In: Valverde, R. (2007). Comunicação intramolecular de longo alcance entre domínios de fosforização regulatória e catalítica em Ccc2p, a $\mathrm{Cu}$ (I)-ATPase de levedura: papel dual da proteína cinase A (PKA). 
A criação do roteiro geral do espetáculo partiu da noção de construção pelo enviroment (Cohen, 1999: 2). Esta noção implicou na ideia de que o roteiro foi instaurado por um processo de espacialização a partir do croqui científico que reuniu em si diferentes extratos e simbologias da encenação. Desta forma o processo de criação coreográfica tomou como ponto de partida a valorização de cenas com projeções de animações tridimensionais junto com a movimentação dos dançarinos. Foi dentro destes pressupostos que utilizou-se o croqui científico citado como um dos eixos norteadores da instauração do roteiro de encenação do espetáculo "Transições". A roteirização coreográfica foi encaminhada nesta pesquisa a partir de conceitos presentes no modelo de regulação e homeostasia do cobre em leveduras, a partir do qual surgiram as cenas "Proliferações", "Transições," "Passagens" e "Chaperonas", (figura 1) conforme a esquematização abaixo:

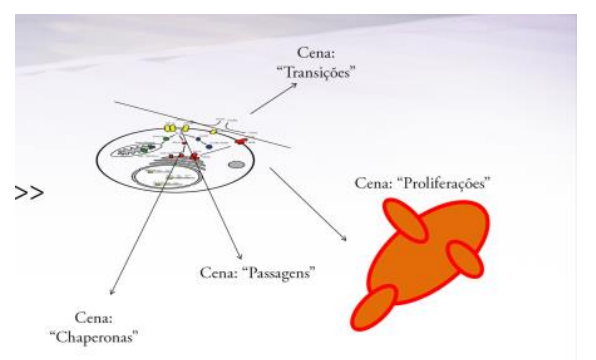

Fig. 1: o croqui científico como instaurador de cenas coreográficas.

Este modelo gráfico funcionou de modo recorrente neste espetáculo, como uma espécie de "partitura" que gerou mapas referenciais da montagem coreográfica, como abaixo indicado (figura 2).

Rio de Janeiro, (Tese de Doutorado) Programa de Pós-Graduação em Ciências Biológicas, IBCCF-UFRJ. 


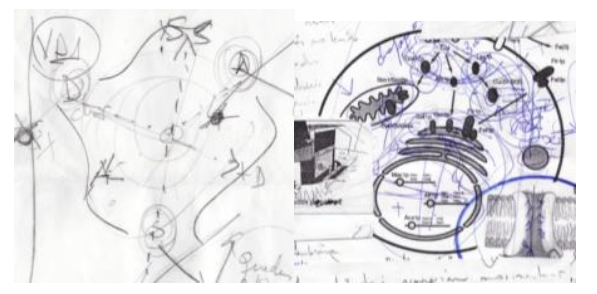

Fig. 2: Mapas de montagem coreográfica gerados a partir do croqui científico.

Verificamos que este tipo de construção de roteiro coreográfico, sob o ponto de vista da análise do grafismoicônico presente na obra de Françõis Dagognet, pode ser considerado como uma condensação ideo-motriz que permite um eclodir de múltiplas frases e cenas coreográficas.

Com a definição da ambientação cênica e do formato do palco, pode-se encadear a montagem da roteirização e montagem coreográfica em um todo integrado com o projeto de projeção. $\mathrm{Na}$ ambientação cênica, o perímetro do croqui foi estruturado em três superfícies dispostas em um formato sinuoso. Com a finalidade de dar maior leveza à cenografia, foi realizado um desalinhamento do perímetro do desenho da levedura. 0 perímetro foi seccionado em três superfícies côncavas e convexas de tecidos que funcionavam como "membranas" dispostas em espiral. Assim, o ambiente cenográfico foi conformado numa espécie de videoinstalação, concebida para ocorrer em três telas desalinhadas que foram fixadas como uma mandala no centro de palco formato italiano, conforme esquema a seguir (figura 3 ).

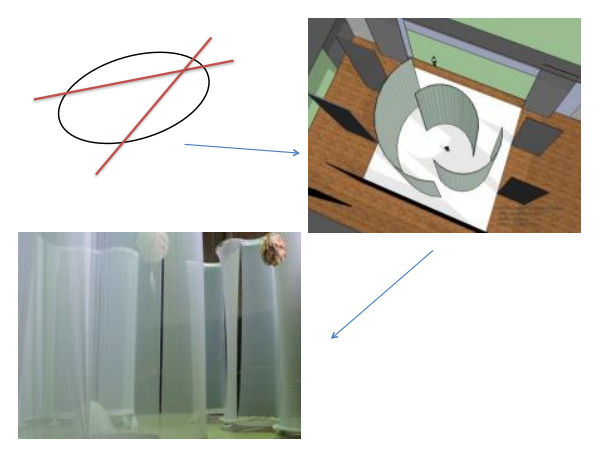

Fig. 3: Desalinhamento do perímetro do desenho da levedura na criação da cenografia. 
Atráves de sucessivas etapas, chegou-se ao modelo final da ambientação cênica, como uma videoinstalação baseada na recriação do desenho da célula de levedura presente no croqui científico (figura 4).

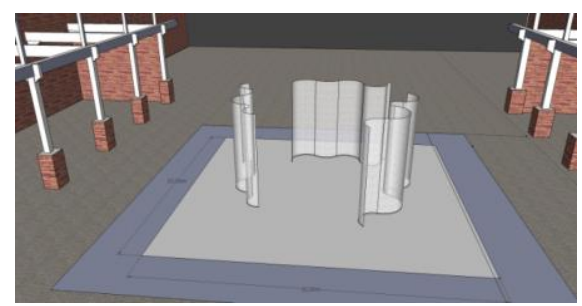

Fig. 4: Vista frontal da maquete virtual do cenário final.

Este modelo final de cenografia foi instalado no Centro Cultural Ação da Cidadania na estréia do espetáculo, conforme pode-se ver abaixo (figuras 5 e 6):
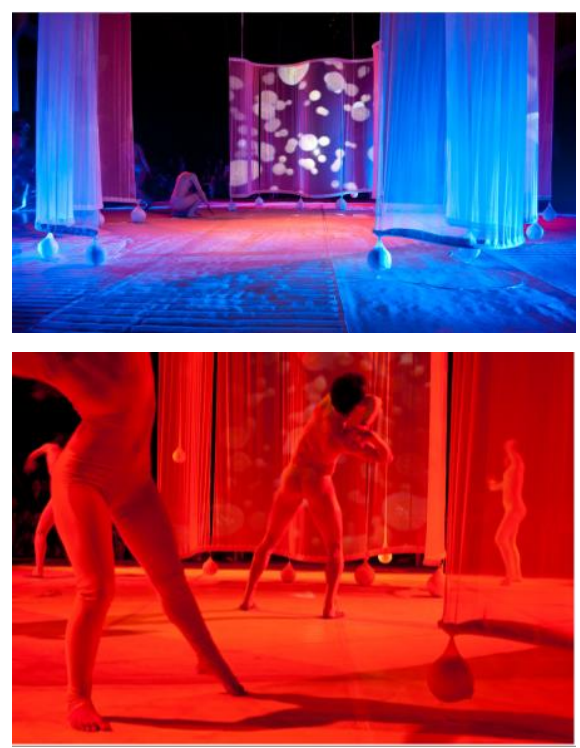

Fig. 5 e 6: apresentações na II Feira FAPERJ Ciência, Tecnologia \& Inovação realizada em 2011.

O espetáculo tem cenas com poesias ${ }^{6}$ como recurso estético para a inserção da informação científica no contexto poético da encenação. Estas poesias procuravam falar da célula e dos

\footnotetext{
${ }^{6}$ Desenvolvido pela poetisa de Daniela Szwertszarf, cujos textos permeiam esta subseção.
} 
fenômenos bioquímicos utilizando uma linguagem poética. As poesias deveriam esclarecer algo sobre o processo de regulação e homeostasia do cobre. O processo de regulação e homeostasia do cobre é caracterizado como um paradoxo. Os metais pesados como cobre, ferro, manganês, cobalto e zinco são elementos essenciais aos seres vivos. Entretanto, a maioria destes metais é tóxica para a célula quando presentes em concentrações mais elevadas. A informação científica foi transcrita em forma poética nos seguintes termos:

\begin{abstract}
De volta me lanço ao paradoxo do cobre. Formulemo-lo assim: elemento essencial e letal, te faz viver, mas te pode matar. O cobre. Elemento são e doentio, doce e amargo, duplo e uno como os pensamentos do inferno oriundos... / formulemo-lo assim: em baixíssimas concentrações, o cobre é essencial a todos os seres. No entanto, ao atingir altas concentrações, o cobre se torna tóxico. Para superar este paradoxo, chegou-se, com a evolução, a um processo regulatório.
\end{abstract}

Dentro da homeostasia do cobre, que é o processo regulatório em questão, é de importância crucial o momento em que o cobre consegue penetrar no meio intracelular. Assim pode-se traduzir poeticamente este momento da seguinte forma:

Agora, atenção. As portas da membrana abrem-se como asas de anjo no fundo do oceano. As portas da membrana se abrem. Um tráfego intenso, um microfervilhar. Já está lá dentro, o cobre. Já é o nosso segredo. Estamos no limiar. Um desvio e o cobre escapa para o perigo...

O perigo para o qual o cobre pode escapar é o perigo do excesso de cobre no meio intracelular, que foi descrito poeticamente nos seguintes termos:

... antes do perigo, porém, as chaperonas encaminham o cobre a outra proteína, denominada cobre-ATPase que, por sua vez, encaminha o cobre ao Complexo de Golgi, onde ele ficará então estocado, pronto para ser excretado. É, assim, então, que as proteínas guiam o cobre e protegem a célula, como se elas fossem 0 exército da salvação. Como se tudo nelas almejasse o outro, todas súditas do músculo coração... 
A projeção mapeada foi realizada a partir de uma série de composições videográficas feitas com imagens do espaço sideral e com microscopia electronica ${ }^{7}$ (figuras 7, 8 e 9).

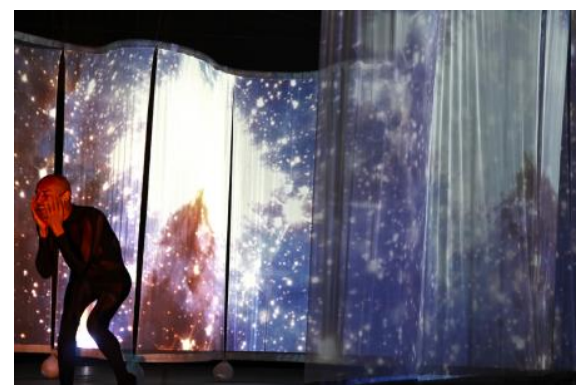

Fig. 7: Diógenes Lima na cena "Prólogo no Céu".

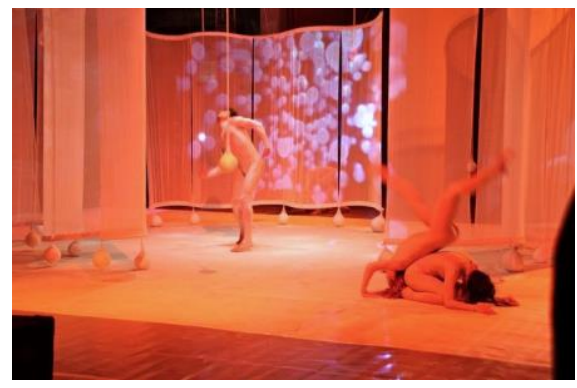

Fig. 8: pesquisa de movimento baseada na proliferação celular na cena "Proliferações".

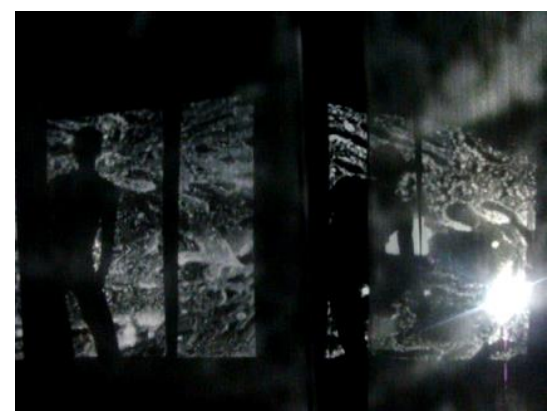

Fig. 9: microscopia eletrônica de varredura junto com a movimentação coreográfica na cena "Chaperonas".

Os processos de criação de "Transições" conjugam ciência, arte e tecnologia propondo um mergulho no mundo do ínfimo

${ }^{7}$ Cedidas pelo Laboratório de Ultra Estrutura Celular Herta Meyer Instituto de Biosífica Carlos Chagas Filho - IBCCF da UFRJ. 
para desvelar a riqueza palpitante do universo bioquímico que escapa aos nossos olhos.

Processos experimentais em dança e música de "Anatomia dos Contatos"

"Anatomia dos Contatos" se caracteriza como uma peça de dança e música contemporânea que mescla campos performáticos diversos e une questões da música contemporânea - desde sons da respiração, sons onomatopáicos, ruídos eletroacústicos, sonoridades desconstruídas, guitarra estruturada e percussão sinfônica com o processo experimental de pesquisa dos contatos e apoios do corpo em movimento. Neste sentido, Schafer esclarece que:

Hoje todos os sons pertencem a um campo contínuo de possibilidades, situado dentro do domínio abrangente da música. Eis a nova orquestra: o universo sônico! E os novos músicos: qualquer um e qualquer coisa que soe ! (1992: 121).

Neste contexto, características como o uso do timbre como foco na construção dos materiais musicais, técnicas instrumentais estendidas, o afrouxamento da fronteira entre compositor e intérprete, procedimentos de improvisação e abertura na obra musical, promovem um diálogo direto com os processos criativos de investigação dos contatos e apoios a partir dos Fundamentos da Dança de Helenita Sá Earp.

Neste contexto, os movimentos de uma mesma parte do corpo, entre partes do corpo, em diferentes bases, com mudanças de base e em diferentes Famílias da Dança 8 e entre as Famílias da Dança, tanto do indivíduo com ele mesmo quanto em

\footnotetext{
${ }^{8}$ Famílias da Dança envolvem o estudo dos movimentos do corpo como um todo organizados de acordo com suas características estruturais. As Famílias da Dança são as Transferências, Locomoções, Voltas, Saltos, Quedas e Elevações.
} 
relação ao outro, ao grupo e ao ambiente móvel e imóvel; foram explorados a partir de diferentes relações com sons onomatopaicos, sílabas, palavras, frases, vocalizes, poesias, percussão corporal, com objetos sonoros e acompanhamento musical (figura 10).

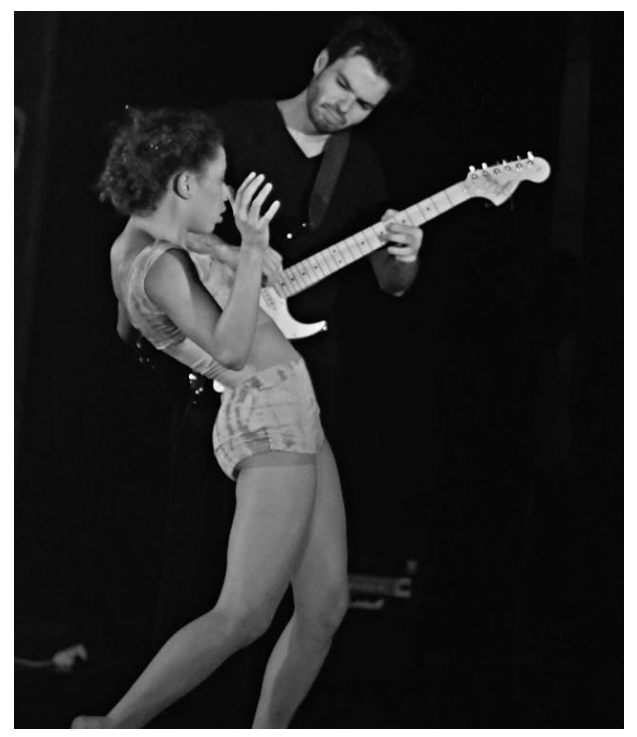

Fig. 10: Tais Almeida da Silva e Rafael Sarpa na interação entre guitarra estruturada e movimento.

Com este suporte teórico e metodológico, a pesquisa coreográfica enfocou a exploração de diferentes contatos e apoios com a produção de sons nas partes do corpo e entre partes e no corpo como um todo, tanto do indivíduo com ele mesmo, como em duplas, em trios e em pequenos grupos (figura 11)

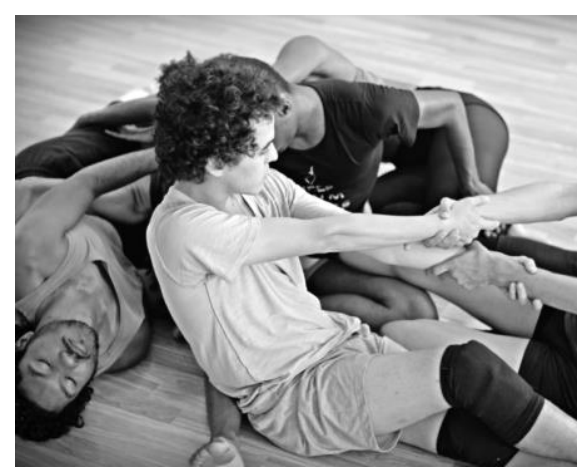

Fig. 11: Ronábio Lima, Antonio Jefferson Maciel e Lucas Oliveira explorando contatos e apoios com produção de sons. 
Todo este processo se desenvolveu em aulas de técnica criativa e de improvisações de estudo das possibilidades de combinações das partes e segmentos do corpo em situações de contato e apoio em diferentes bases de sustentação (figuras 12,13 e 14).
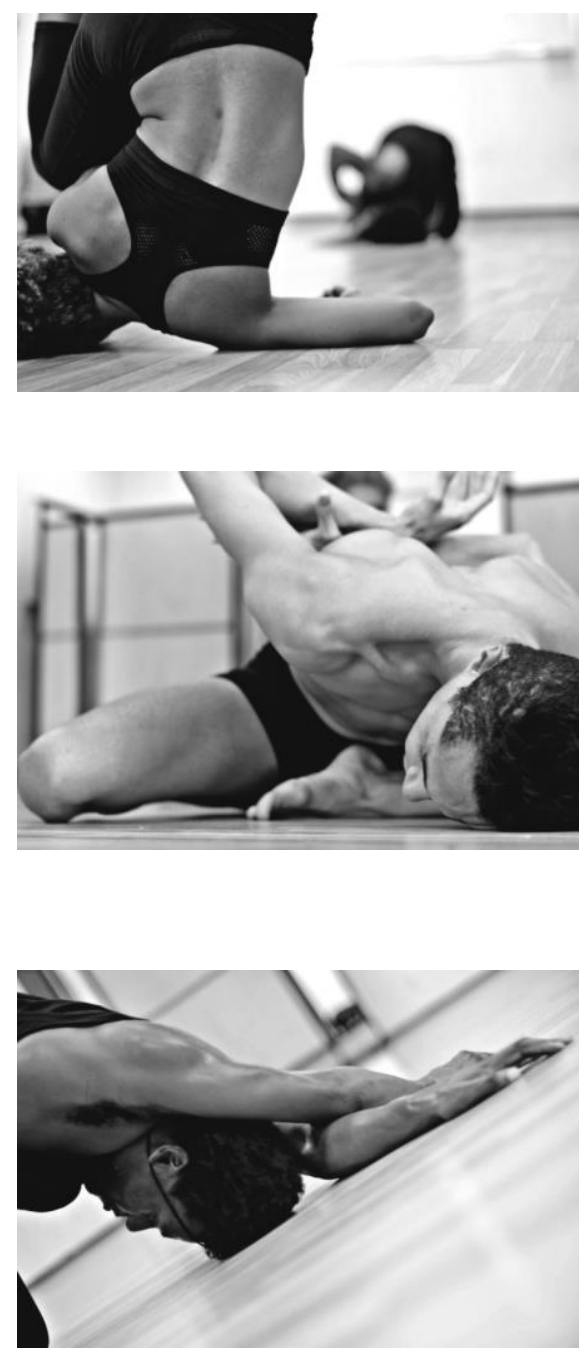

Fig. 12, 13 e 14: Sílvia Patrícia dos Santos, Bruno Damião e Jefferson do Nascimento e explorando contatos e apoios em diferentes bases de sustentação ${ }^{9}$

Estas situações instauraram a criação de movimentos com sons produzidos pela respiração, voz, percussão corporal, objetos e instrumentos musicais presentes na cena, gerando

${ }^{9}$ Fotografias de Julius Mack (figuras 10, 11, 12, 13 e 14). 
diversas interfaces frutíferas a ambos os universos da dança e da música contemporâneas. É partindo desta pluralidade que o diálogo entre dança e música se instaura em "Anatomia dos Contatos", explorando diretamente de que forma muitos dos elementos desenvolvidos no universo musical com o advento do século $X X$ e sua continuação nesta nova virada de século podem contribuir para a pesquisa e a montagem coreográfica nos protocolos de criação da Companhia de Dança Contemporânea da UFRJ.

\section{Resultados e considerações finais}

O espetáculo "Transições" foi apresentado na II Feira FAPERJ Ciência, Tecnologia e Inovação, na FeSBE 2011 e no VIII Congresso Brasileiro de Farmácia Homeopática. "Anatomia dos Contatos" foi apresentada como obra em processo na Semana Nacional de Ciência e Tecnologia - UFRJ 2013, no Evento "Dançar - Contemporâneo" realizado no Centro Cultural Fundação Companhia Siderúrgica Nacional - Volta Redonda/RJ e no I Fórum de Arte e Cultura do Instituto Federal de Educação Fluminense - Campos/RJ.

Os Fundamentos da Dança de Helenita Sá Earp permitem que se formem constelações de redes, advinda da interação da linguagem da dança com as demais manifestações artísticas e científicas na constituição de múltiplos enfoques de encenação coreográfica. Justamente por enfatizar princípios e referenciais que fornecem suportes para a criação de disponibilidades múltiplas nas diferenças dos corpos e suas possíveis aplicações numa técnica criativa na dança, a pesquisa ilimitada das possibilidades de manifestação do movimento, sempre envolvem o desenvolvimento da intuição e os aspectos cognitivos, afetivos e motores da corporeidade. Essas possibilidades de conexões ilimitadas permitem a criação de metodologias diversas de ensino e criação em dança que tende a gerar uma fluidez entre diferentes linguagens artísticas e entre diferentes áreas do conhecimento. 


\section{Referências}

Bulcão, M. (2010). O Gozo do Conhecimento e da Imaginação: François Dagognet diante da Ciência e da Arte Contemporânea. Rio de Janeiro: Mauad X.

Cohen, R. (1999). Work in Progress na Cena Contemporânea. São Paulo: Perspectiva.

Dagognet, F. (1975). Ecriture et Iconographie. Paris: J. Vrin.

Earp, A. (2010). Princípios de conexões dos movimentos básicos em suas relações anátomo-cinesiológicas na dança segundo Helenita Sá Earp. Disponível em: < http://www.portalabrace.org/vicongresso/pesquisadanca/Ana\%20C\% E9lia\%20S\%E1\%20Earp\%20\%20Princ\%EDpios\%20de\%20conex\%F5es\%20segundo\%20H.\%20E arp.pdf> Acessado em: 05/02/2015.

Earp, R. (1992). Aspectos Comuns da Matemática, da Metafísica e das Artes. Revista Unimar, Universidade Estadual de Maringá, n. 14, v. 1, p.75-93.

Meyer, A. (2012). Dança e Ciência: Estudo acerca de Processos de Roteirização e Montagem Coreográfica baseados em Formas e Padrões de Organização Biológicos a partir dos Fundamentos da Dança de Helenita Sá Earp. Tese (doutorado). Rio de Janeiro: UFRJ. http://fenix3.ufrj.br/50/teses/d/CCS_D_AndreMeyerAlvesDeLima.pdf Michaud, Y. (1984). Extérieur sans intérieur, corps sans âme? In Canguilhem, G; Debru, C; Escat, G; Guéry, F; Lambert, J; Moulin, A. Anatomie d'un épistémologue: Françõis Dagognet. Paris: J. Vrin.

Schafer, M. (1992). O ouvido pensante. São Paulo: Unesp.

Shaw, J. (1999). Editorial. In Forsythe, W. Improvisation Technologies - a tool for the analytical dance eye. Karlsruhe: ZKM Digital Arts Editions. 